\title{
Clinical characteristics and outcome of critically ill COVID-19 patients with acute kidney injury: a single centre cohort study
}

R. Lowe ${ }^{1}$, M. Ferrari ${ }^{1}$, M. Nasim-Mohi ${ }^{1}$, A. Jackson 1,3, R. Beecham ${ }^{1}$, K. Veighey ${ }^{2}$, R. Cusack ${ }^{1,3,4}$, D. Richardson ${ }^{1}$, MPW Grocott ${ }^{1,3,4}$, DZH Levett ${ }^{1,3,4}$, A. Dushianthan ${ }^{1,3,4^{*}}$ and an behalf of the University Hospital Southampton Critical Care Team and the REACT COVID investigators

\begin{abstract}
Background: Acute kidney injury (AKI) is a common manifestation among patients critically ill with SARS-CoV-2 infection (Coronavirus 2019) and is associated with significant morbidity and mortality. The pathophysiology of renal failure in this context is not fully understood, but likely to be multifactorial. The intensive care unit outcomes of patients following COVID-19 acute critical illness with associated AKI have not been fully explored. We conducted a cohort study to investigate the risk factors for acute kidney injury in patients admitted to and intensive care unit with COVID-19, its incidence and associated outcomes.

Methods: We reviewed the medical records of all patients admitted to our adult intensive care unit suffering from SARS-CoV-2 infection from 14th March 2020 until 12th May 2020. Acute kidney injury was defined using the Kidney Disease Improving Global Outcome (KDIGO) criteria. The outcome analysis was assessed up to date as 3rd of September 2020.

Results: A total of 81 patients admitted during this period. All patients had acute hypoxic respiratory failure and needed either noninvasive or invasive mechanical ventilatory support. Thirty-six patients (44\%) had evidence of AKI (Stage I-33\%, Stage II-22\%, Renal Replacement Therapy (RRT)-44\%). All patients with AKI stage III had RRT. Age, diabetes mellitus, immunosuppression, lymphopenia, high D-Dimer levels, increased APACHE II and SOFA scores, invasive mechanical ventilation and use of inotropic or vasopressor support were significantly associated with AKI. The peak AKI was at day 4 and mean duration of RRT was 12.5 days. The mortality was $25 \%$ for the AKI group compared to $6.7 \%$ in those without AKI. Among those received RRT and survived their illness, the renal function recovery is complete and back to baseline in all patients.
\end{abstract}

Conclusion: Acute kidney injury and renal replacement therapy is common in critically ill patients presenting with COVID-19. It is associated with increased severity of illness on admission to ICU, increased mortality and prolonged ICU and hospital length of stay. Recovery of renal function was complete in all survived patients.

Keywords: COVID-19, Intensive care, Acute kidney injury

\footnotetext{
* Correspondence: a.dushianthan@soton.ac.uk

${ }^{1}$ General Intensive Care Unit, University Hospital Southampton NHS

Foundation Trust, Tremona Road, Southampton SO16 6YD, England

${ }^{3} \mathrm{NIHR}$ Southampton Clinical Research Facility and NIHR Southampton

Biomedical Research Centre, University Hospital Southampton / University of

Southampton, Tremona Road, Southampton SO16 6YD, England

Full list of author information is available at the end of the article
}

(c) The Author(s). 2021 Open Access This article is licensed under a Creative Commons Attribution 4.0 International License, which permits use, sharing, adaptation, distribution and reproduction in any medium or format, as long as you give appropriate credit to the original author(s) and the source, provide a link to the Creative Commons licence, and indicate if changes were made. The images or other third party material in this article are included in the article's Creative Commons licence, unless indicated otherwise in a credit line to the material. If material is not included in the article's Creative Commons licence and your intended use is not permitted by statutory regulation or exceeds the permitted use, you will need to obtain permission directly from the copyright holder. To view a copy of this licence, visit http://creativecommons.org/licenses/by/4.0/ The Creative Commons Public Domain Dedication waiver (http://creativecommons.org/publicdomain/zero/1.0/) applies to the data made available in this article, unless otherwise stated in a credit line to the data. 


\section{Background}

SARS-CoV-2 viral infection leading to Coronavirus 2019 (COVID-19) was declared as an emerging pandemic by the World Health Organization (WHO) in March 2020 [1]. The first case was reported in the United Kingdom (UK) on the 31st January and patient numbers rose rapidly with a corresponding increase in admissions to hospital and intensive care units (ICU) over the subsequent months. Although the majority of infected patients developed mild or no respiratory symptoms, a proportion progressed to severe lung disease characterised by acute hypoxic respiratory failure (AHRF) necessitating respiratory support or mechanical ventilation. Acute kidney injury (AKI) is relatively common in both hospitalised and critically ill COVID-19 patients [2, 3]. In a multicentre study of more than 3000 COVID-19 ICU patients from the United States America, around 20\% developed acute kidney injury (AKI) requiring renal replacement therapy [3]. Similarly, in the UK, during the first wave of the pandemic a quarter of intensive care unit COVID-19 patients needed renal replacement therapy [4]. Furthermore, AKI may be associated with an ongoing requirement for renal support and prolonged hospitalization thereby imposing a significant health and resource burden.

The pathophysiology of AKI in COVID-19 is poorly understood but may involve a combination of pre-renal and intrinsic renal insults. Studies have described the virus' affiliation for the angiotensin converting enzyme-2 (ACE-2) receptor, which is expressed in abundance in the kidney $[5,6]$. The virus also directly infects tubular epithelial cells and podocytes causing significant structural damage [7]. Proteinuria and haematuria have been commonly documented and may be indicative of intrinsic renal injury [2, 8-10]. Post-mortem findings of COVID-19 patients suggest micro-vascular occlusion, endothelial injury, diffuse acute proximal tubular injury and evidence of direct damage as a consequence of SARS CoV-2 infection [7].

The majority of critically ill patients with COVID-19 require ventilatory support, but the clinical manifestations of COVID-19 vary and the characteristics and outcomes of patients with AKI have not been fully defined. Consequently we aimed to characterise the risk factors for AKI in intensive care patients with Covid-19, its incidence and patient outcomes in a single centre cohort study.

\section{Methods}

This study was conducted in a General Intensive Care Unit (GICU) at the University Teaching Hospital in Southampton (UHS), UK. All adult patients ( $>18$ years old) admitted between $14 / 03 / 2020$ and $12 / 05 / 2020$ to the Intensive Care Unit with a diagnosis of COVID-19 confirmed via a reverse-transcriptase-polymerase-chain- reaction (RT-PCR) test were included in this study. The respiratory samples were taken from nasal and throat swabs or endotracheal tube aspirates for confirmatory analysis. Ethical approval was obtained as part of the REACT COVID observational study (A longitudinal Cohort Study to facilitate Better understanding and Management of SARS-CoV-2 infection from hospital admission to discharge across all levels of care): REC Reference 10/NW/0632 SRB Reference Number; SRB0025. Due to the nature of the study, the need for individual informed consent was waived.

Data was collected from an electronic clinical record system (Meta-vision, iMDsoft). This included baseline demographics, past medical history, pre-hospital medication, timings of disease onset, laboratory test results, ventilator strategies and clinical information regarding renal supportive measures and outcomes. Comorbidities included; diabetes mellitus, ischæmic heart disease, hypertension, chronic kidney disease, immunosuppression and congestive cardiac failure. We further quantified the severity of comorbidities using the Charlson's comorbidity index [11]. Disease severity on admission to the ICU was assessed by the Acute Physiology and Chronic Health Evaluation II (APACHE II) score, Sequential Organ Failure Assessment (SOFA) score and degree of hypoxia from the ratio of arterial oxygen partial pressure $\left(\mathrm{PaO}_{2}\right.$ in $\mathrm{kPa}$ and $\left.\mathrm{mmHg}\right)$ to fractional inspired oxygen $\left(\mathrm{PaO}_{2} / \mathrm{FiO}_{2}\right.$ ratio or $\mathrm{P} / \mathrm{F}$ ratio).

Acute kidney injury was defined based by the Kidney Disease Improving Global Outcome (KDIGO) classification which depends on the serum creatinine profile during the hospital admission [12]. Briefly, AKI was detected when there is an increase in serum creatinine (SCr) by $\geq 26.5 \mu \mathrm{mol} / \mathrm{L}$ within $48 \mathrm{~h}$ or increase in $\mathrm{SCr}$ to $>1.5$ times baseline occurred within the prior 7 days. Staging was classified as stage I when 1.5-1.9 times, stage II 2.0-2.9 times (or $\geq 26.5 \mu \mathrm{mol} / 1$ increase) and stage III 3 times increment (or $>353.6 \mu \mathrm{mol} / \mathrm{l}$ increase or initiation of renal replacement therapy) from the baseline serum creatinine. As baseline we used either an estimated $\mathrm{SCr}$ or the lowest $\mathrm{SCr}$ in the first week of admission. If creatinine was found to be elevated at presentation, we reviewed the case notes for historical results within 1 year to determine if this was an acute process. If there were no historical blood results, then an estimated baseline creatinine was used to grade the AKI according to their gender, ethnicity and age (according to KDIGO criteria) [12]. Renal function recovery is defined as improvement in creatinine below 1.5 times the baseline or estimated creatinine. All admitted patients were divided into two groups; patients with AKI and without AKI. The use of vasopressors and diuretics with additional information of cumulative daily fluid balance was also documented. 
Descriptive statistics were used to characterize the clinical variables of patients in the AKI and no AKI groups. The Kolmogorov-Smirnov was used to evaluate normality in continuous data. Direct comparisons between the AKI and no AKI groups were performed with the Mann-Whitney U (continuous variables) and Fisher's exact tests (categorical variables).

\section{Results}

Between 14th of March and 12th of May 2020, a total of 81 critically ill COVID-19 patients were admitted to the Intensive Care Unit. The median age was 57 (IQR 18) and $62 \%$ were male. The median duration of symptoms prior to hospitalisation was 7 days (IQR 5). $56.8 \%$ were white and $48.1 \%$ had a raised BMI of $>30 \mathrm{~kg} / \mathrm{m}^{2}$. For those with baseline creatinine available, chronic kidney disease was evident in 5 patients $(8.3 \%)$ and one patient was receiving long-term dialysis for end stage renal failure secondary to diabetic nephropathy. The comorbidities recorded were diabetes mellitus (25.9\%), hypertension (37\%) and immunosuppression (9.9\%). Of patients with immunosuppression; 3 patients had Human Immunodeficiency Virus infection (HIV), 2 had hematological malignancies, 2 were on immunosuppressive medications for autoimmune diseases and one undergoing chemoradiotherapy for intracerebral solid tumor. Twenty patients (24.7\%) were documented to be on prescription medication of either an angiotensin converting enzyme II (ACE II) inhibitor or an angiotensin receptor blocker (ARB).

Thirty-six patients (44.4\%) had an AKI at any time during their ICU stay. Of these, 12 (33.3\%) had AKI stage I, $8(22.2 \%)$ had AKI stage II and 16 patients (44.5\%) had AKI stage III and received renal replacement therapy (RRT) (Fig. 1).

The patients with AKI were older (61 vs 50, $p=$ 0.0071 ) with increased comorbidities as quantified by Carlson's comorbidity index (2.5 vs $1, p=0.0016)$ and had a higher incidence of diabetes mellitus $(38.9 \%$ vs $15.6 \%, p=0.0225)$ and immunosuppression (19.4\% vs $2.2 \%, p=0.0193$ ) (Table 1). Patients with AKI had greater illness severity as determined by APACHE II (20 vs $12, p<0.0001$ ) and SOFA (5 vs $3, p=0.0001$ ) scores. The degree of acute hypoxic respiratory failure was similar in the two groups: $\mathrm{PaO}_{2} / \mathrm{FiO}_{2}$ ratio (P/F ratio) of 14.4 vs $15.4 \mathrm{kPa}$ or $108 \mathrm{vs} 115 \mathrm{mmHg}, p=0.0811)$. However, AKI patients were more likely to have received invasive mechanical ventilation $(86.1 \%$ vs $37.8 \%, p=0.0001)$ and vasopressor or inotropic support $(91.7 \%$ vs $35.6 \%, \mathrm{p}=$ $0.0001)$. The use of diuretics and corticosteroids were also more common in patients with AKI. The clinical characteristics of all patients are presented in Table 1.

On admission, patients with AKI had lower lymphocyte counts and higher D-Dimer, troponin and creatinine levels (Table 1). The lymphopenia with raised levels

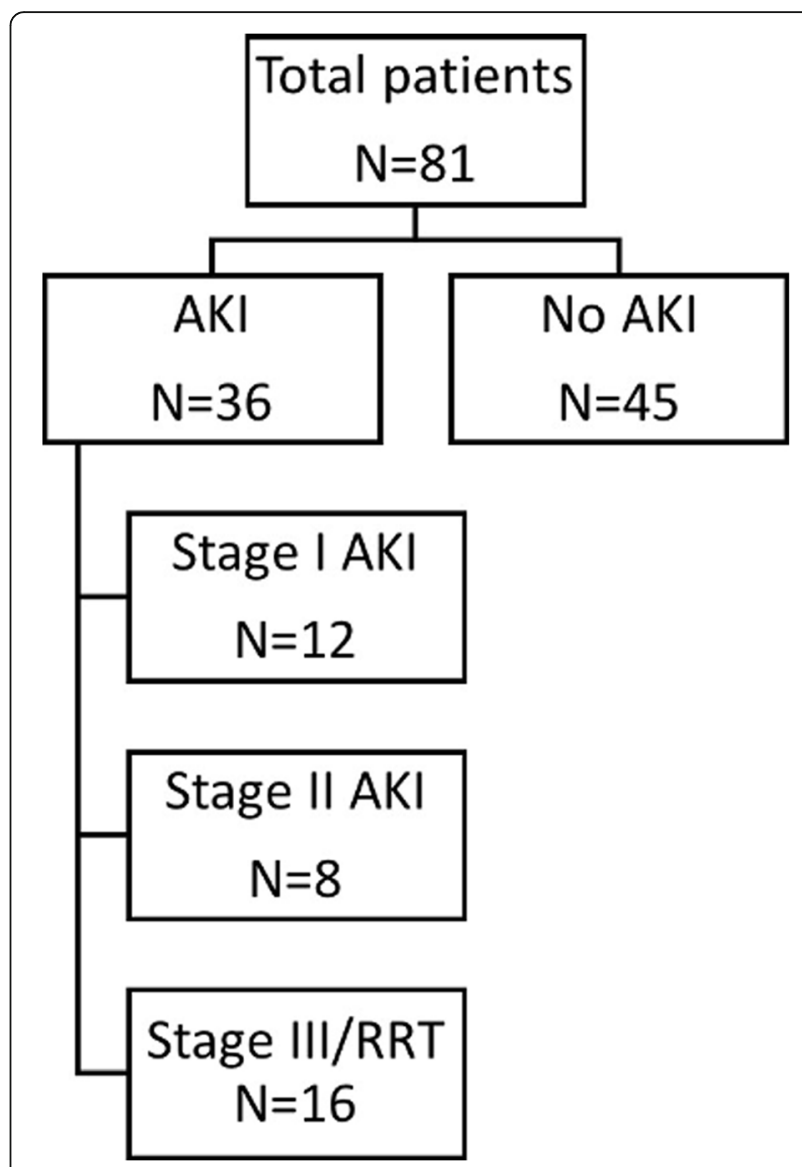

Fig. 1 COVID-19 patient flow diagram. AKl, Acute Kidney Injury; RRT, Renal Replacement Therapy. The Acute Kidney Injury is defied according to the Kidney Disease Improving Global Outcomes (KDIGO) criteria

of D-Dimers persisted even at day 7 and in patients without AKI, whereas lymphocyte count in those without AKI continue to increase after the ICU admission (Fig. 2) and Additional file 1.

The daily fluid balance analysis showed more positive fluid balance in the AKI group at day $1(+670 \mathrm{mls}, 95 \%$ $\mathrm{CI}:+1165$ to $+143, P=0.01)$ and day $2(+497 \mathrm{mls}, 95 \%$ CI: +880 to $+28, P=0.04$ ) (Fig. 3 ). For patients admitted to ICU with AKI, the median time from (we calculated from ICU admission) to documented peak AKI was 4 days (IQR 6 days) and the median peak AKI from symptom onset was 10.5 days (IQR 7.3 days). For patients who received RRT, the median time to commencing RRT was 5 days (IQR 6 days) after admission to the intensive care unit and the median duration of RRT was 12.5 days (IQR 15.5 days). The mode of renal support was primarily continuous veno-venous hemodiafiltration (CVVHDF) with citrate anticoagulation. Out of the 16 patients who received RRT, 10 received additional formal therapeutic anticoagulation with intravenous heparin. A standard augmented anticoagulation protocol 
Table 1 Patient demographics on admission, disease severity indices, intensive care interventions and admission laboratory markers from all COVID-19 admitted patients

\begin{tabular}{|c|c|c|c|c|}
\hline Demographics & All patients $(N=81)$ & AKI $(N=36)$ & No AKI $(N=45)$ & $P$-value \\
\hline Age, years & $57(18)$ & $61(14)$ & $50(16)$ & $P=0.0071^{*}$ \\
\hline Male (\%) & $62 \%$ & $66.7 \%$ & $57.8 \%$ & $P=0.4930$ \\
\hline Symptomatic days prior to hospitalisation & $7(5)$ & $7(7)$ & $8(4)$ & $P=0.1183$ \\
\hline $\mathrm{BMI} \geq 30$ kg/m², n (\%) & $29(48.1 \%)$ & $21(58.3 \%)$ & $18(40 \%)$ & $P=0.1208$ \\
\hline Charlson's comorbidity index & $2(2)$ & $2.5(3)$ & 1(3) & $P=0.0016^{*}$ \\
\hline \multicolumn{5}{|l|}{ Race/ethnic group } \\
\hline White & $46(56.8 \%)$ & $24(66.7 \%)$ & $22(48.9 \%)$ & $P=0.1209$ \\
\hline Black & $7(8.6 \%)$ & $4(11.1 \%)$ & $3(6.7 \%)$ & $P=0.6941$ \\
\hline Asian/Indian & $20(24.7 \%)$ & $5(13.9 \%)$ & $15(33.3 \%)$ & $P=0.0684$ \\
\hline Other/unknown & $8(9.9 \%)$ & $3(8.3 \%)$ & $5(11.1 \%)$ & $P=0.7274$ \\
\hline \multicolumn{5}{|l|}{ Comorbidities, n (\%) } \\
\hline Chronic kidney disease & $5(6.2 \%)$ & $3(8.3 \%)$ & $2(4.4 \%)$ & $P=0.6511$ \\
\hline Congestive cardiac failure & $4(4.9 \%)$ & $2(5.6 \%)$ & $2(4.4 \%)$ & $P=1.0000$ \\
\hline Diabetes mellitus & $21(25.9 \%)$ & $14(38.9 \%)$ & $7(15.6 \%)$ & $P=0.0225^{*}$ \\
\hline Hypertension & $30(37 \%)$ & $15(41.7 \%)$ & 15 (33.3\%) & $P=0.4924$ \\
\hline Ischemic heart disease & $7(8.6 \%)$ & $2(5.6 \%)$ & $5(11.1 \%)$ & $P=0.4537$ \\
\hline Immunosuppression & $8(9.9 \%)$ & 7 (19.4\%) & $1(2.2 \%)$ & $P=0.0193^{*}$ \\
\hline Use of ACEi or ARB & $20(24.7 \%)$ & $10(27.8 \%)$ & $10(22.2 \%)$ & $P=0.6111$ \\
\hline \multicolumn{5}{|l|}{ Severity indices } \\
\hline APACHE II Score & $14(12)$ & $20(11.2)$ & $12(6)$ & $P<0.0001^{*}$ \\
\hline SOFA Score & $4(3)$ & $5(3)$ & $3(1)$ & $P=0.0001^{*}$ \\
\hline $\mathrm{PaO}_{2} / \mathrm{FiO}_{2}$ ratio & & & & $P=0.0811$ \\
\hline $\mathrm{kPa}$ & $15(5)$ & $14.4(4.5)$ & $15.4(4.8)$ & \\
\hline $\mathrm{mmHg}$ & $112.5(37.5)$ & $108(33.7)$ & $115.5(36)$ & \\
\hline \multicolumn{5}{|l|}{ ICU interventions } \\
\hline Mechanical ventilation, n (\%) & $48(59.3 \%)$ & $31(86.1 \%)$ & $17(37.8 \%)$ & $P=0.0001^{*}$ \\
\hline Non-invasive ventilation, n (\%) & $33(40.7 \%)$ & $5(13.9 \%)$ & $27(60 \%)$ & $P=0.0001^{*}$ \\
\hline Vasopressor use, n (\%) & 49 (60.5\%) & $33(91.7 \%)$ & $16(35.6 \%)$ & $P=0.0001^{*}$ \\
\hline Vasopressor use > 1 type, n (\%) & $15(18.5 \%)$ & $13(36.1 \%)$ & $2(4.4 \%)$ & $P=0.0003^{*}$ \\
\hline Diuretics use, n (\%) & $49(60.5 \%)$ & $27(75.0 \%)$ & $22(48.9 \%)$ & $P=0.0225^{*}$ \\
\hline Diuretics use > 1 type, n (\%) & $20(24.7 \%)$ & $14(38.9 \%)$ & $6(13.3 \%)$ & $P=0.0090^{*}$ \\
\hline Corticosteroids & $23(28.4 \%)$ & $15(41.7 \%)$ & $8(17.8 \%)$ & $P=0.0255^{*}$ \\
\hline Pulmonary vasodilators, n (\%) & $11(13.6 \%)$ & $8(22.2 \%)$ & $3(6.67 \%)$ & $P=0.0544$ \\
\hline Antibiotics (any), n (\%) & $81(100 \%)$ & $36(100 \%)$ & $45(100 \%)$ & $P=1.0000$ \\
\hline Antivirals (any), n (\%) & $25(31.9 \%)$ & $12(33.3 \%)$ & $13(28.9 \%)$ & $P=0.8093$ \\
\hline \multicolumn{5}{|l|}{ Admission laboratory profile } \\
\hline Bilirubin $(\mathrm{mmol} / \mathrm{l})$ & $11(6)$ & $11(9)$ & $11(5)$ & $P=0.8939$ \\
\hline Creatinine (mmol/l) & $72(44)$ & $98(84)$ & $65(28)$ & $P=0.0222^{*}$ \\
\hline Creatinine kinase $(\mathrm{U} / \mathrm{l})$ & $160(240)$ & $153(411)$ & $174(237)$ & $P=0.8105$ \\
\hline C-Reactive Protein (mg/l) & $153(106)$ & $166(135)$ & $125(82)$ & $P=0.0598$ \\
\hline D-Dimer (mg/l) & $527(742)$ & $942(2157)$ & $444(395)$ & $P=0.0318^{*}$ \\
\hline Ferritin (mg/l) & $965(1430)$ & $842(963)$ & 989 (1601) & $P=0.9087$ \\
\hline $\mathrm{HbA} 1 \mathrm{c}(\mathrm{mmol} / \mathrm{mol})$ & $46(9)$ & $48(10)$ & $44.5(8)$ & $P=0.0615$ \\
\hline
\end{tabular}


Table 1 Patient demographics on admission, disease severity indices, intensive care interventions and admission laboratory markers from all COVID-19 admitted patients (Continued)

\begin{tabular}{lllll}
\hline Demographics & All patients $(\boldsymbol{N}=\mathbf{8 1})$ & AKI $(\boldsymbol{N}=\mathbf{3 6})$ & No AKI $(\boldsymbol{N}=\mathbf{4 5})$ & $P$-value \\
\hline LDH $(\mathrm{U} / \mathrm{l})$ & $909(572)$ & $1026(721)$ & $909(550)$ & $1.000(0.6)$ \\
Lymphocytes $10^{9} / \mathrm{l}$ & $0.9(0.7)$ & $0.700(0.7)$ & $8.7(5.4)$ & $P=0.9745$ \\
Neutrophil/lymphocyte ratio & $7.8(6.8)$ & $8.7(6.2)$ & $0.0133^{*}$ \\
Procalcitonin $(\mathrm{ng} / \mathrm{ml})$ & $0.3(0.6)$ & $0.6(0.9)$ & $9(0.5)$ & $P=0.1010$ \\
HS Troponin $(\mathrm{ng} / \mathrm{l})$ & $13(26.5)$ & $27.5(117)$ & $9(8)$ & $P=0.1076$ \\
White cell counts $10^{9} / \mathrm{I}$ & $8.2(6.5)$ & $8.9(7)$ & $7.6(5.7)$ & $P=0.0001^{*}$ \\
\hline
\end{tabular}

Data are presented as median (Interquartile Range) or numbers (percentage) unless otherwise stated. ${ }^{*} P<0.05$ as assessed by Fisher's Exact test for categorical variables and Mann-Whitney U test for continuous variables. ACEi Angiotensin Converting Enzyme inhibitor, APACHE II Acute Physiology and Chronic Health Evaluation II score, ARB Angiotensin Receptor Blocker, $B M I$ Body Mass Index, $L D H$ Lactate dehydrogenase, $\mathrm{HS}_{\mathrm{T}}$ Troponin High Sensitivity Troponin, $\mathrm{PaO}_{2} /$ FiO ${ }_{2}$ Ratio of arterial oxygen partial pressure to fractional inspired oxygen, SOFA Sequential Organ Failure Assessment score

was utilised for all COVID-19 patients includ- admitted to ICU with AKI was 25\% (9/36), compared ing for those with an AKI (see Additional file 2).

Outcomes are up to date as of 3st of September 2020. Among those who developed AKI and survived their acute COVID-19 illness, all patients (27/27) have fully recovered to their baseline renal function (Fig. 4). The overall hospital mortality for the patients to $6.7 \%,(3 / 45)$ in those without AKI. One patient remains hospitalised for rehabilitation (Table 2). Overall, twelve patients died. For those patients with completed outcomes, the median length of ICU and hospital stay was significantly longer in patients with AKI at 28 (IQR 34) and 39.5 days (IQR 36.5)

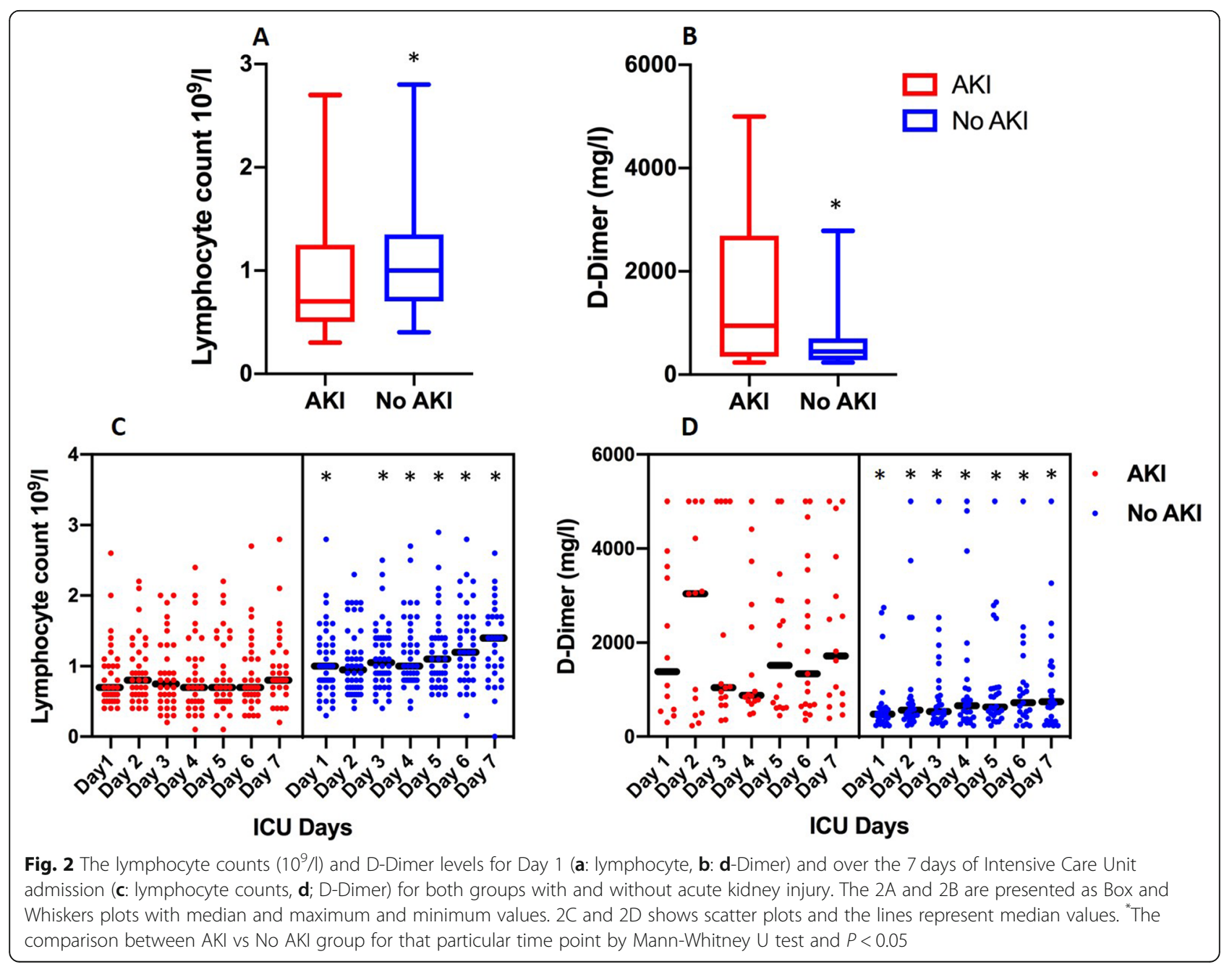




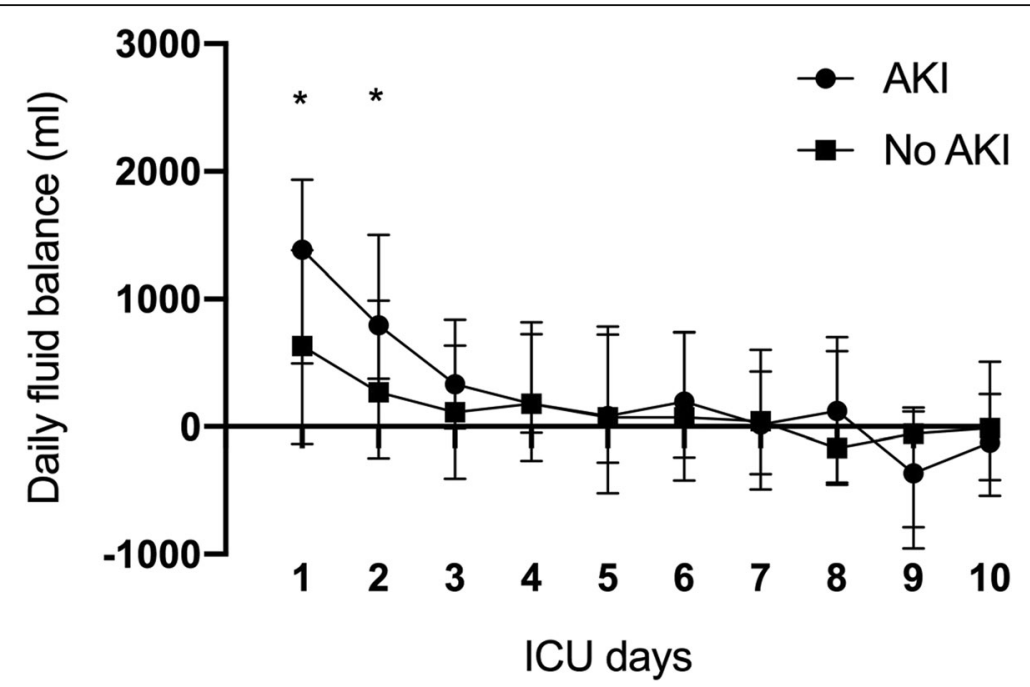

Fig. 3 Daily cumulative fluid balance for patients with and without AKI for the first 10 days of ICU admission. Data is presented as median and interquatile ranges. ${ }^{*}$ The comparison between AKI vs No AKI group for that particular time point by Mann-Whitney $U$ test and $P<0.05$

compared to 5.5 days (IQR 11) and 15.5 days (IQR 14 days) for without AKI, respectively.

\section{Discussion}

In this study, we report that $45 \%$ of COVID-19 patients admitted to intensive care for respiratory support developed an AKI and $20 \%$ of the total ICU cohort required renal replacement therapy acutely for an average duration of 12.5 days. Overall hospital mortality for critically ill ICU patients with COVID-19 was $15 \%$, compared to $25 \%$ in patients with AKI. All survived patients with AKI stage I and II and stage III/RRT had complete recovery to their baseline renal function. Risk factors for the development of AKI were older age, preexisting diabetes mellitus and immunosuppression for any reason including HIV, myelosuppression due to hematological malignancies and immunosuppressive therapy. AKI was associated with increased disease severity on admission (APACHE II and SOFA scores), mechanical ventilation, persistently raised D-Dimer and more severe lymphopenia.

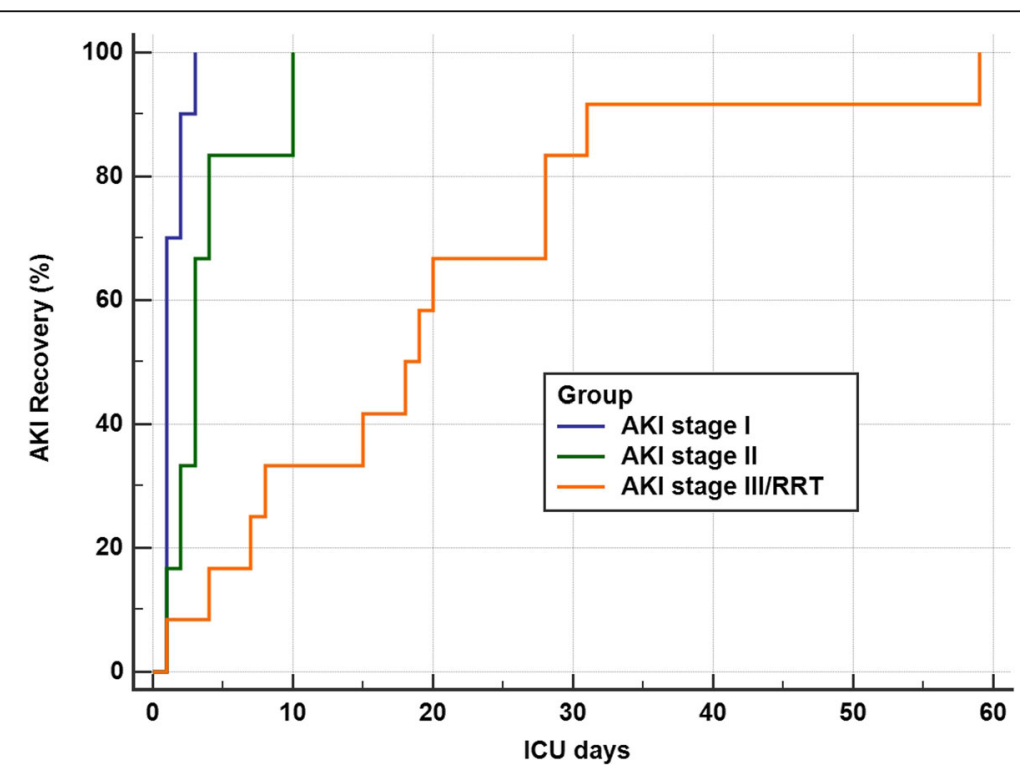

Fig. 4 The recovery of acute kidney injury across all stages of AKI as defined by the Kidney Disease Improving Global Outcomes (KDIGO) criteria over time during the intensive care unit stay. The RRT group recovery is defined as normalisation of renal function off renal replacement therapy. AKI, Acute kidney injury; ICU, Intensive Care Unit; RRT, Renal Replacement Therapy 
Table 2 Outcome of all patients with and without acute kidney injury

\begin{tabular}{lll}
\hline Outcomes & Patients with AKI $(\boldsymbol{N}=\mathbf{3 6})$ & Patients without AKI $(\boldsymbol{N}=\mathbf{4 5})$ \\
\hline Length of RRT & $12.5(10.8)$ & N/A \\
Length of ICU Stay & $28(34)$ & $5.5(11)$ \\
Length of Hospital Stay & $27(23)$ & $15.5(14)$ \\
Death & $9(25.0 \%)$ & $3(6.7 \%)$ \\
Still Hospitalised & $1(2.8 \%)$ & $0(0 \%)$ \\
Still in ICU & $0(0 \%)$ & $0(0 \%)$ \\
Still on RRT & $1^{\text {a }}$ & N/A \\
Discharged Home & $19(72.2 \%)$ & $42(93.3 \%)$ \\
\hline
\end{tabular}

AKI Acute Kidney Injury, ICU Intensive Care Unit, RRT Renal Replacement Therapy. Data are presented as median (Interquartile Range) or numbers (percentage) unless otherwise stated. ${ }^{a}$ One patient had CKD with established long-term dialysis programme

AKI is an independent risk factor for increased mortality in all critical illness [13, 14]. The reported incidence of AKI among critically ill COVID 19 patients in earlier cohorts from China was approximately $20-30 \%$ and it is regarded as a marker of disease severity $[15,16]$. Although the incidence of AKI in our cohort is higher than these early reports, it is comparable to the other international studies from Brazil [17] and USA [3]. Our renal replacement rate is also comparable to the reports from larger cohorts with a rate of $20-31 \%$ [3, 4]. However, in studies of mostly invasively ventilated critically ill COVID 19 patients, the incidence of AKI was reported to be as high as $75 \%$ with an RRT rate of $17.7-51 \%$ [10, $18,19]$. In contrast, our cohort was inclusive of patients with noninvasive ventilation, which may account for the difference in AKI prevalence, RRT rate and mortality.

Our finding of increased mortality in patients with AKI (25\% vs 6.7\%) is in keeping with other COVID-19 case cohorts $[8,9,20,21]$. Patients with AKI had more severe illness generally, required invasive mechanical ventilation, had higher illness severity scores, persistent lymphopenia and vasopressor support, suggesting that AKI is a marker of disease severity. Immunosuppression for any reason was associated with increased incidence of AKI. It is possible that patients who are immunocompromised may have an increased severity of COVID-19 critical illness predisposing them to develop AKI [22].

The cumulative daily fluid balance suggests more positive fluid balance in the AKI group for the first $48 \mathrm{~h}$ of ICU admission. This in combination with the increased frequency of vasopressor and corticosteroids usage suggests that patients with AKI were sicker than patients without AKI. Among our all AKI cases, the mortality for the AKI groups, Stage I, Stage II and the RRT group are 25,25 and $27 \%$ respectively. This is lower than the $56 \%$ national mortality in patients receiving RRT reported in the UK ICNARC outcome dataset and from other international studies $[3,4,18]$. Patients in our RRT cohort had similar age and acute severity indices (APACHE II of $21, \mathrm{PaO}_{2} / \mathrm{FiO}_{2} 15.1 \mathrm{kPa}$ or $113 \mathrm{mmHg}$ ) with higher mechanical ventilation rate $(100 \%)$ and $92 \%$ had vasoactive agents as advanced cardiovascular support suggesting this group is comparable to the ICNARC dataset [4]. While we are unable to postulate the exact reasoning behind this better survival rate, it is likely to be multifactorial and is reflection of variations in patient's population, resource availability and ICU interventions.

Although the exact pathophysiological mechanism of AKI in COVID-19 remains elusive, it appears to be multifactorial. Direct viral infection [7, 23], overt immune response leading to tubuloepithelial injury [24] and microvascular endothelial injury due to microthrombi formation $[25,26]$ are some of the underlying pathophysiological mechanisms postulated. The contribution of microthrombi formation in AKI has been found in postmortem findings, where there is erythrocyte stagnation with clot formation in the glomerular and peri-tubular capillaries in COVID-19 patients [6]. Moreover, one study demonstrated that elevated DDimer level and complete failure of lysis at $30 \mathrm{~min}$ on a thromboelastogram are predictive of significant increase in the incidence of thromboembolism and a need for haemodialysis in critically ill COVID-19 patients [26]. In our report, the development of AKI was associated with raised admission D-dimer levels and these abnormalities persisted in patients with AKI even after a week of ICU admission. This supports the fore-mentioned studies and highlights this maybe a potential contributor to the underlying pathophysiology of AKI in COVID-19 cases.

Interestingly, the use of diuretics was much more common in patients with AKI. Diuretics are often used in the intensive care setting to enhance a judicious fluid balance to improve oxygenation in patients with acute severe hypoxic respiratory failure. It is not clear whether the increased usage of diuretics contributed to the development of AKI or whether they were used to facilitate urine output and consequently improve fluid balance when AKI was already established. Similarly, AKI patients were more likely to be treated with corticosteroids. The use of corticosteroids probably reflects a more 
severe disease process and it is not possible to make any direct conclusions regarding cause and effect from this study.

Our study has several limitations. Firstly, this is a small cohort study of patients admitted with COVID-19 characterised by acute hypoxic respiratory failure and needing respiratory support may not be representative of all hospitalised COVID-19 patients. Secondly, the laboratory testing for D-Dimer was not consistently measured for all patients and the missing values may have introduced bias. Moreover, there was an upper limit cutoff for D-Dimer values of $5000 \mathrm{mg} / \mathrm{l}$ and as a result, we were unable to present the absolute laboratory values for levels beyond $>5000 \mathrm{mg} / \mathrm{l}$. Finally, we did not perform additional renal specific urine biological investigations to characterize the AKI which limits our ability to evaluate the mechanism of renal injury. Whilst we recognise these limitations, we were still able to identify factors associated with the development of AKI and outcome of AKI recovery. Reassuringly, all but one patient who recovered from their acute illness have also completely recovered from their acute kidney injury.

\section{Conclusions}

Acute kidney injury is a common feature in critically ill patients with COVID-19 pneumonia presenting with acute hypoxic respiratory failure. It is more common in patients with immunosuppression, hypertension and diabetes. The development of AKI is associated with increased severity of illness, prolonged duration of hospitalisation and increased mortality. Reassuringly, all surviving patients recovered from their acute kidney injury over time prior to their hospital discharge.

\section{Abbreviations \\ ACE: Angiotensin converting enzyme; AHRF: Acute hypoxic respiratory failure; AKI: Acute kidney injury; APACHE II: Acute Physiology and Chronic Health Evaluation II; ARB: Angiotensin receptor blocker; COVID-19: Coronavirus disease 2019; CWHDF: Continuous veno-venous hemodiafiltration; HIV: Human immunodeficiency virus; ICU: Intensive care unit; KDIGO: Kidney Disease Improving Global Outcome; RRT: Renal replacement therapy; SARS- CoV-2: Severe acute respiratory syndrome coronavirus 2; SOFA: Sequential Organ Failure Assessment; WHO: World Health Organisation}

\section{Supplementary Information}

The online version contains supplementary material available at https://doi. org/10.1186/s12882-021-02296-z.

Additional file 1: Table S1. Lymphocyte count $10^{9} /$ over the 7 days (Data presented in median (IQR)). Table S2. D-Dimer (mg/l) over the 7 days.

Additional file 2. The standard anticogulation protocol used in all ICU patients.

\section{Authors' contributions}

Conception and design: $R L, A J, R D$, and $A D$. Data Collection and analysis: $R L$, $M F, M N M, J A, R M$ and $A D$. Manuscript Preparations: RL, KV, RC, RD, MG, DL,
AD. Critical revision of manuscript: All authors. All authors approved the summitted version.

Funding

No funding for the study.

\section{Availability of data and materials}

The datasets used and/or analysed during the current study available from the corresponding author on reasonable request.

\section{Declarations}

\section{Ethics approval and consent to participate}

Ethical approval was obtained as part of the REACT COVID observational study (A longitudinal Cohort Study to facilitate Better understanding and Management of SARS-CoV-2 infection from hospital admission to discharge across all levels of care): REC Reference 17/NW/0632 SRB Reference Number; SRB0025. Due to the nature of the study, the need for individual informed consent was waived.

\section{Consent for publication}

Not applicable.

\section{Competing interests}

The authors declare that they have no competing interests.

\section{Author details}

${ }^{1}$ General Intensive Care Unit, University Hospital Southampton NHS Foundation Trust, Tremona Road, Southampton SO16 6YD, England. ${ }^{2}$ Renal Medicine, University Hospital Southampton NHS Foundation Trust, Tremona Road, Southampton SO16 6YD, England. ${ }^{3} \mathrm{NIHR}$ Southampton Clinical Research Facility and NIHR Southampton Biomedical Research Centre, University Hospital Southampton / University of Southampton, Tremona Road, Southampton SO16 6YD, England. ${ }^{4}$ Faculty of Medicine, University of Southampton, University Hospital Southampton, Tremona Road,

Southampton SO16 6YD, England.

Received: 11 September 2020 Accepted: 8 March 2021

Published online: 15 March 2021

\section{References}

1. Organisation WH. Coronavirus disease (COVID-19) pandemic. 2019. https:// www.who.int/emergencies/diseases/novel-coronavirus-2019. Accessed 19 June 2020.

2. Hirsch JS, Ng JH, Ross DW, Sharma P, Shah HH, Barnett RL, Hazzan AD, Fishbane S, Jhaveri KD, Abate M, Andrade HP, Barnett RL, Bellucci A Bhaskaran MC, Corona AG, Chang BF, Finger M, Fishbane S, Gitman M, Halinski C, Hasan S, Hazzan AD, Hirsch JS, Hong S, Jhaveri KD, Khanin Y, Kuan A, Madireddy V, Malieckal D, Muzib A, Nair G, Nair W, Ng JH, Parikh R, Ross DW, Sakhiya V, Sachdeva M, Schwarz R, Shah HH, Sharma P, Singhal PC, Uppal NN, Wanchoo R, Bessy Suyin Flores Chang, Ng JH. Acute kidney injury in patients hospitalized with Covid-19. Kidney Int. 2020;98(1):209-18. https://doi.org/10.1016/j.kint.2020.05.006.

3. Gupta S, Coca SG, Chan L, Melamed ML, Brenner SK, Hayek SS, Sutherland A, Puri S, Srivastava A, Leonberg-Yoo A, Shehata AM, Flythe JE, Rashidi A, Schenck EJ, Goyal N, Hedayati SS, Dy R, Bansal A, Athavale A, Nguyen HB, Vijayan A, Charytan DM, Schulze CE, Joo MJ, Friedman AN, Zhang J, Sosa MA, Judd E, Velez JCQ, Mallappallil M, Redfern RE, Bansal AD, Neyra JA, Liu KD, Renaghan AD, Christov M, Molnar MZ, Sharma S, Kamal O, Boateng JO, Short SAP, Admon AJ, Sise ME, Wang W, Parikh CR, Leaf DE, the STOPCOVID Investigators. AKI treated with renal replacement therapy in critically ill patients with COVID-19. J Am Soc Nephrol. 2021;32(1):161-76. https://doi. org/10.1681/ASN.2020060897.

4. Intensive Care National Audit \& Research Centre. Report on COVID-19 in critical care. 2020. https://www.icnarc.org/Our-Audit/Audits/Cmp/Reports. Accessed 19 June 2020.

5. Martinez-Rojas MA, Vega-Vega O, Bobadilla NA. Is the kidney a target of SARS-CoV-2? Am J Physiol Physiol. 2020;318:1454-62.

6. Batlle D, Soler MJ, Sparkes MA, et al. Acute kidney injury in COVID-19: emerging evidence of a distinct pathophysiology. J Am Soc Nephrol. 2020; 31(7):1380-3. https://doi.org/10.1681/ASN.2020040419. 
7. Su H, Yang M, Wan C, Yi LX, Tang F, Zhu HY, Yi F, Yang HC, Fogo AB, Nie X, Zhang C. Renal histopathological analysis of 26 postmortem findings of patients with COVID-19 in China. Kidney Int. 2020;98(1):219-27. https://doi. org/10.1016/j.kint.2020.04.003.

8. Cheng Y, Luo R, Wang K, Zhang M, Wang Z, Dong L, Li J, Yao Y, Ge S, Xu G. Kidney disease is associated with in-hospital death of patients with COVID19. Kidney Int. 2020;97(5):829-38. https://doi.org/10.1016/j.kint.2020.03.005.

9. Pei G, Zhang Z, Peng J, Liu L, Zhang C, Yu C, Ma Z, Huang Y, Liu W, Yao Y, Zeng $\mathrm{R}$, Xu G. Renal involvement and early prognosis in patients with COVID-19 pneumonia. J Am Soc Nephrol. 2020;31(6):1157-65. https://doi. org/10.1681/ASN.2020030276.

10. Cummings MJ, Baldwin MR, Abrams D, Jacobson SD, Meyer BJ, Balough EM, Aaron JG, Claassen J, Rabbani LRE, Hastie J, Hochman BR, Salazar-Schicchi J, Yip NH, Brodie D, O'Donnell MR. Epidemiology, clinical course, and outcomes of critically ill adults with COVID-19 in New York City: a prospective cohort study. Lancet. 2020;395(10239):1763-70. https://doi.org/1 0.1016/S0140-6736(20)31189-2.

11. Charlson ME, Pompei P, Ales KLMC. A new method of classifying prognostic comorbidity in longitudinal studies: development and validation. J Chronic Dis. 1987;40(5):373-83. https://doi.org/10.1016/0021-9681(87)90171-8.

12. Kellum JA, Lameire N, Aspelin P, Barsoum RS, Burdmann EA, Goldstein SL, et al. Kidney disease: improving global outcomes (KDIGO) acute kidney injury work group. KDIGO clinical practice guideline for acute kidney injury. Kidney Int Suppl. 2012;2:1-138

13. Kolhe NV, Stevens PE, Crowe AV, Lipkin GW, Harrison DA. Case mix, outcome and activity for patients with severe acute kidney injury during the first 24 hours after admission to an adult, general critical care unit: application of predictive models from a secondary analysis of the ICNARC case mix Programme data. Crit Care. 2008;12:1-13.

14. Hoste EA, Bagshaw SM, Bellomo R, et al. Epidemiology of acute kidney injury in critically ill patients: the multinational AKI-EPI study. Intensive Care Med. 2015;41(8):1411-23. https://doi.org/10.1007/s00134-015-3934-7.

15. Yang X, Yu Y, Xu J, Shu H, Xia J', Liu H, Wu Y, Zhang L, Yu Z, Fang M, Yu T, Wang Y, Pan S, Zou X, Yuan S, Shang Y. Clinical course and outcomes of critically ill patients with SARS-CoV-2 pneumonia in Wuhan, China: a singlecentered, retrospective, observational study. Lancet Respir Med. 2020;8(5): 475-81. https://doi.org/10.1016/S2213-2600(20)30079-5.

16. Yu Y, Xu D, Fu S, Zhang J, Yang X, Xu L, et al. Patients with COVID-19 in 19 ICUs in Wuhan, China: a cross-sectional study. Crit Care. 2020;24:1-10.

17. Doher MP, Torres de Carvalho FR, Scherer PF, Matsui TN, Ammirati AL, Caldin da Silva B, et al. Acute kidney injury and renal replacement therapy in critically ill COVID-19 patients: risk factors and outcomes: a single-center experience in Brazil. Blood Purif. 2020;18:1-11. https://doi.org/10.1159/ 000513425 Epub ahead of print.

18. Thakkar J, Chand S, Aboodi MS, Gone AR, Alahiri E, Schecter DE, et al. Characteristics, Outcomes and 60-day Hospital Mortality of ICU patients with COVID-19 and Acute Kidney Injury. Kidney. 2020;1:1339-44.

19. Fominskiy EV, Scandroglio AM, Monti G, Calabrò MG, Landoni G, Dell'Acqua A, Beretta L, Moizo E, Ravizza A, Monaco F, Campochiaro C, Pieri M, Azzolini ML, Borghi G, Crivellari M, Conte C, Mattioli C, Silvani P, Mucci M, Turi S, Tentori S, Baiardo Redaelli M, Sartorelli M, Angelillo P, Belletti A, Nardelli P. Nisi FG, Valsecchi G, Barberio C, Ciceri F, Serpa Neto A, Dagna L, Bellomo R, Zangrillo A, for the COVID-BioB Study Group. Prevalence, characteristics, risk factors, and outcomes of invasively ventilated COVID-19 patients with acute kidney injury and renal replacement therapy [published online ahead of print, 2020 Jul 13]. Blood Purif. 2020;1 (1):1-8. https://doi.org/10.1159/ 000508657.

20. Ali H, Daoud A, Mohamed MM, Salim SA, Yessayan L, Baharani J, Murtaza A, Rao V, Soliman KM. Survival rate in acute kidney injury superimposed COVID-19 patients: a systematic review and meta-analysis. Ren Fail. 2020; 42(1):393-7. https://doi.org/10.1080/0886022X.2020.1756323.

21. Wang Y, Shi L, Yang H, Duan G, Wang Y. Acute kidney injury is associated with the mortality of coronavirus disease 2019. J Med Virol. 2020;92(11): 2335-7. https://doi.org/10.1002/jmv.26019.

22. Fung M, Babik JM. COVID-19 in Immunocompromised Hosts: What We Know So Far. Clin Infect Dis. 2020;1:ciaa863. https://doi.org/10.1093/cid/ciaa 863 Epub ahead of print.

23. Fan C, Li K, Ding Y, Lu WL, Wang J. ACE2 Expression in Kidney and Testis May Cause Kidney and Testis Damage After 2019-nCoV Infection. medRxiv. 2020;30(10):118. https://doi.org/10.1101/2020.02.12.20022418.
24. Diao B, Wang C, Tan Y, Chen X, Liu Y, Ning L, et al. Reduction and functional exhaustion of T cells in patients with coronavirus disease 2019 (COVID-19). Front Immunol. 2020;11:1-7.

25. Helms J, Tacquard C, Severac F, Leonard-Lorant I, Ohana M, Delabranche X, et al. High risk of thrombosis in patients with severe SARS-CoV-2 infection: a multicenter prospective cohort study. Intensive Care Med. 2020;46(6):108998. https://doi.org/10.1007/s00134-020-06062-x.

26. Wright FL, Vogler TO, Moore EE, Moore HB, Wohlauer MV, Urban S, Nydam $T L$, Moore PK. Fibrinolysis shutdown correlates to thromboembolic events in severe COVID-19 infection. J Am Coll Surg. 2020;231(2):193-203.e1. https:// doi.org/10.1016/j.jamcollsurg.2020.05.007.

\section{Publisher's Note}

Springer Nature remains neutral with regard to jurisdictional claims in published maps and institutional affiliations.
Ready to submit your research? Choose BMC and benefit from:

- fast, convenient online submission

- thorough peer review by experienced researchers in your field

- rapid publication on acceptance

- support for research data, including large and complex data types

- gold Open Access which fosters wider collaboration and increased citations

- maximum visibility for your research: over $100 \mathrm{M}$ website views per year

At BMC, research is always in progress.

Learn more biomedcentral.com/submissions 